\title{
Characterization of low molecular weight dissolved natural organic matter along the treatment trait of a waterworks using Fourier transform ion cyclotron resonance mass spectrometry
}

\author{
Haifeng Zhang ${ }^{a}$, Yahe Zhang ${ }^{b}$, Quan Shi ${ }^{b}$, Shuoyi Ren ${ }^{a, b}$, Jianwei Yu ${ }^{a}$, Feng Ji ${ }^{c}$, \\ Wenbin Luo ${ }^{c}$, Min Yang ${ }^{a, *}$ \\ a State Key Laboratory of Environmental Aquatic Chemistry, Research Center for Eco-Environmental Sciences, Chinese Academy of Sciences, \\ P. O. Box 2871, Beijing 100085, China \\ ${ }^{\mathrm{b}}$ State Key Laboratory of Heavy Oil Processing, China University of Petroleum, Beijing 102249, China \\ ${ }^{\mathrm{C}}$ Centre of Water Quality, Harbin Water Supply and Drainage Group, Harbin 150080, China
}

\section{A R T I C L E I N F O}

Article history:

Received 10 March 2012

Received in revised form

14 June 2012

Accepted 3 July 2012

Available online 21 July 2012

Keywords:

Coagulation

Chlorination

DOM

Electrospray ionization

ESI FT-ICR MS

\begin{abstract}
A B S T R A C T
Dissolved natural organic matter (DOM), particularly the low molecular weight DOM, can affect the performance of water treatment processes and serve as a main precursor of disinfection by-products (DBPs) during chlorination. In this study, electrospray ionization coupled to Fourier transform ion cyclotron resonance mass spectrometry (ESI FT-ICR MS) was used to characterize the low molecular weight DOM along the treatment trait of a conventional drinking water treatment plant. The ESI FT-ICR MS data showed that various $\mathrm{C}, \mathrm{H}$, O-only class species were the major components in the source water. According to the van Krevelen diagram analysis, lignin- and tannin-like compounds were the most abundant components. Within an isobaric group, the DOM molecules with a high degree of oxidation (high $\mathrm{O} / \mathrm{C}$ value) were preferentially removed during coagulation, while those with low degree of oxidation were found to be more reactive toward chlorine. In addition, 357 one-chlorine containing products and 199 two-chlorine containing products formed during chlorination were detected in the chlorination effluent sample at a high confidence level. The chlorinated products can be arranged into series, suggesting that they were originated from $\mathrm{C}, \mathrm{H}$, O-only precursor compounds, which were in series related by the replacement of $\mathrm{CH}_{4}$ against oxygen. For the first time, this study explored the behavior of low molecular weight DOM along a drinking water treatment trait on the molecular level, and revealed the presence of abundant unknown chlorinated products, which are probably rich in carboxylic and phenolic groups, in drinking water.
\end{abstract}

(c) 2012 Elsevier Ltd. All rights reserved.

\footnotetext{
* Corresponding author. Tel.: +8610 62923475; fax: +861062923541.

E-mail address: yangmin@rcees.ac.cn (M. Yang). 


\section{Introduction}

Dissolved natural organic matter (DOM), which is a heterogeneous mixture of complex organic matter, is extensively present in all kinds of drinking source water. DOM has been considered to negatively affect the performance of water treatment processes including coagulation, activated carbon adsorption and membrane filtration (Aoustin et al., 2001). It may not only cause adverse aesthetic qualities such as color, taste and odor, but also form a variety of harmful disinfection by-products (DBPs) during disinfection of drinking water (Richardson, 1998; Richardson et al., 2007; Hua and Reckhow, 2007) by reacting with chlorine, and promote undesired microbial growth in water distribution systems (Richardson et al., 2007). With such a big impact on drinking water quality, improved knowledge of DOM, such as molecular compositions and their behaviors during water treatment, is of great importance.

Because DOM may contain literally thousands or even millions of different chemical compositions, it is unrealistic to characterize it on the basis of a thorough compilation of the individual compounds. Bulk characteristics of different fractions of DOM have been effectively determined by numerous analytical techniques, such as elemental analysis (EA), ultraviolet/visible (UV/Vis) spectroscopy, Fourier-transform infrared (FTIR) spectroscopy, fluorescence excitation/emission matrix (EEM) spectroscopy, nuclear magnetic resonance (NMR) and pyrolysis GC/MS (Berwick et al., 2010; Minor and Stephens, 2008; McDonald et al., 2004; Li et al., 2000; Roccaro et al., 2009; Cook, 2004; Abbt-Braun et al., 2004). At the same time, membrane separation (Abbt-Braun et al., 2004), ion exchange resin separation (Thurman and Malcolm, 1981) and size exclusion chromatography (Knuutinen et al., 1988), etc., have also been used to characterize DOM's molecular sizes or hydrophilicity. With these efforts, it has now been clear that the low molecular weight, hydrophilic DOM plays an important role in water treatment processes. The low molecular weight DOM, which is difficult to be removed through conventional coagulation (Davis and Gloor, 1981; Chow et al., 1999; Drikas et al., 2003), can decrease the efficiency of activated carbon treatment through competition for adsorption sites with target compounds (Newcombe et al., 1997), and promote biofilm formation in drinking water distribution systems through providing bioavailable organic matter (Hem and Efraimsen, 2001). The existing tools, however, are not able to provide detailed information of the low molecular weight DOM at the molecular level, making it difficult to reveal the reaction mechanisms during treatment processes for achieving better water treatment effects.

Recently, electrospray ionization (ESI) coupled to Fourier transform ion cyclotron resonance mass spectrometry (FT-ICR MS), has emerged as a very promising technique in the characterization of DOM from different water environments (Stenson et al., 2003; Hertkorn et al., 2008; Kim et al., 2006; Sleighter et al., 2009) as well as the biological and photolytic transformation of DOM (Kim et al., 2006; Kujawinski et al., 2002; Kujawinski et al., 2004; Hertkorn et al., 2007; Gonsior et al., 2009). The ultrahigh resolution and mass accuracy of FT-ICR MS provides molecular masses accurate to within
$1 \mathrm{ppm}$, which often enables the determination of molecular formulas by mass measurement alone (Stenson et al., 2003; Kim et al., 2006). It is therefore expected that the FT-ICR MS might help understanding transformations of DOM on a molecular level during water treatment processes, and provide useful information for improving water treatment performance.

In this study, low molecular weight DOM along the treatment trait of a waterworks adopting the conventional treatment process including coagulation, sand filtration and chlorination in succession was characterized using ESI FT-ICR MS. The behaviors of low molecular weight DOM were studied by comparing molecular compositions before and after each treatment. In addition, efforts were made to identify some newly formed chlorine containing products after chlorination by accurate mass analysis using ESI FT-ICR MS data. For the first time, this study provides an overview of how the low molecular weight DOM changed along the water treatment trait, allowing the water supply industry to employ more effective water treatment strategies.

\section{Methods}

\subsection{Sampling and sample preparation}

Water samples were collected in December 2011 from different points along the process train from Mopanshan drinking water treatment plant (DWTP), which supplies water to Haerbin City, China with a capacity of $900,000 \mathrm{~m}^{3} / \mathrm{d}$. Source water for the Mopanshan DWTP was diverted through a $60-\mathrm{km}$ pipe from the Mopanshan reservoir, located in the mountainous area of Heilongiang Province. The treatment train consists of coagulation (with $80 \mathrm{mg} / \mathrm{L}$ polyaluminium chloride, $\mathrm{PACl}$, liquid form containing $10 \%$ of $\mathrm{Al}_{2} \mathrm{O}_{3}$; reaction time, $16 \mathrm{~min}$ ), rapid sand filtration (filtration rate, $42 \mathrm{~cm} / \mathrm{min}$ ) and disinfection with chlorine (liquid chlorine, dose $1.8 \mathrm{mg} / \mathrm{L}$, reaction time $30 \mathrm{~min}$ ). The samples were collected along the process train, according to the hydraulic retention time (HRT). The samples were collected in amber glass bottles and delivered under cooled conditions ( $4{ }^{\circ} \mathrm{C}$ in cooling boxes) within $48 \mathrm{~h}$ to the lab for further processing. Sodium thiosulfate $(20 \mathrm{mg} / \mathrm{L})$ was added to the samples to quench any chlorine residue (Zhang et al., 2012). It should be noted that the addition of sodium thiosulfate might affect the DOM to some extent. It cannot exclude, that the remaining DOM might be modified by reaction with thiosulfate (may be reduction of quinones). Even CHOS components might be produced. Once arrived in the lab, the samples were filtered through $0.45 \mu \mathrm{m}$ Supor filter membranes (Pall, USA) and stored in the dark at $4{ }^{\circ} \mathrm{C}$ until used. The general water quality parameters were measured and listed in Supplemental Information (SI), Table S1.

For the ESI FT-ICR MS measurement, $1 \mathrm{~L}$ water samples were acidified with hydrochloric acid (p.a. grade, Merck, Germany) to pH 2 (Koch et al., 2005; Zhang et al., 2012) and pumped through a Sep-pak C18 solid phase extraction cartridge (1 g, $6 \mathrm{~mL}$, Waters, USA) at a flow rate of $\sim 5 \mathrm{~mL} / \mathrm{min}$. The cartridges were previously rinsed with methanol and acidified ( $\mathrm{pH}$ 2) Milli-Q water. For complete removal of salt, the 
cartridges were rinsed with $20 \mathrm{~mL}$ acidified Milli-Q water before elution. Immediately after extraction, DOM was eluted with $20 \mathrm{~mL}$ LC-MS grade methanol (Merck, Germany). The eluted samples were freeze-dried and stored at $-18^{\circ} \mathrm{C}$ in the dark.

\subsection{FT-ICR MS analysis}

The analyses were performed using a Bruker Apex ultra FT-ICR MS equipped with a $9.4 \mathrm{~T}$ superconducting magnet. DOM sample was dissolved in methanol solution and injected into the electrospray source at $180 \mu \mathrm{L} / \mathrm{h}$ using a syringe pump. The operating conditions for negative-ion formation consisted of a $4.0 \mathrm{kV}$ emitter voltage, $4.5 \mathrm{kV}$ capillary column introduce voltage, and $-320 \mathrm{~V}$ capillary column end voltage. Ions accumulated in the ion source for $0.1 \mathrm{~s}$ in a hexapole. All of the ions passed through a single quadrupole, accumulated in an argonfilled hexapole collision pool, in which ions accumulated for $0.1 \mathrm{~s}$. The delay was set to $1.2 \mathrm{~ms}$ to transfer the ions from the collision pool to an ICR cell by electrostatic focusing of transfer optics. The mass range was set at $\mathrm{m} / \mathrm{z} 150-800$. The data size was set to $4 \mathrm{M}$ words, and time-domain data sets were co-added with 256 acquisitions.

Solvent blanks and C18 extraction blanks were measured. Methanol blank analyses were performed to check if the instrument was clean prior to analyzing the samples. Very few peaks overlapped between the C18 extraction blank and the sample mass spectra. Nonetheless, all peaks found in the blank were removed from the sample peak lists.

\subsection{Mass calibration and data analysis}

The FT-ICR mass spectra were externally calibrated for a mass range of 150-800 using a sodium formate aqueous solution and internally recalibrated with a known homologous series of the DOM sample. The $\mathrm{m} / \mathrm{z}$ values between 200 and $600 \mathrm{Da}$ with relative abundance greater than 6 times the standard deviation of the baseline noise value were exported to a spreadsheet. Data analysis was performed using custom software based on Kendrick mass defect analysis method (Hughey et al., 2001; Qian et al., 2001; Shi et al., 2008).

Molecular compositions of hydrocarbon homologues can be identified by their unique combination of nominal mass and Kendrick mass defect (KMD), and can be expressed as a general chemical formula, $\mathrm{C}_{c} \mathrm{H}_{2 c}+{ }_{z} \mathrm{X}$, in which $c$ is the carbon number, $Z$ is referred to as the hydrogen deficiency index, and $X$ denotes the constituent heteroatoms $(\mathrm{O}, \mathrm{N}, \mathrm{S})$ in a hydrocarbon molecule (Hughey et al., 2001; Qian et al., 2001). For convenience, we can denote a given hydrocarbon "type" and "class" according to its $\mathrm{Z}$ and $\mathrm{X}$ components. For example, $\mathrm{C}_{\mathrm{c}} \mathrm{H}_{2 \mathrm{c}}-{ }_{6} \mathrm{O}_{4}$ is abbreviated as $-6 \mathrm{O}_{4}$, whereas $\mathrm{C}_{c} \mathrm{H}_{2 c}-{ }_{29} \mathrm{NO}$ is listed as $-29 N O$. The $Z$ value is directly related to the number of rings plus double bonds in the molecule. For example, the number of rings plus double bonds in a molecule of chemical formula, $\mathrm{C}_{c} \mathrm{H}_{h} \mathrm{~N}_{n} \mathrm{O}_{o}$, is $(c-h / 2+n / 2+1)$. Each member of a given "type" series has the same $Z$-value (i.e., same number of rings plus double bonds), but may differ by multiples of 14.01565 in International Union of Pure and Applied Chemistry (IUPAC) mass (and by multiples of exactly 14 in Kendrick mass) according to the number of $\mathrm{CH}_{2}$ groups appended to the rings. Members of such a series can therefore be recognized from their identical Kendrick mass defects.

The program first converted measured masses from IUPAC mass scale to the Kendrick mass scale. Even and odd nominal Kendrick masses were then sorted, and the Kendrick mass defect was calculated. Molecular compositions of hydrocarbon homologues were identified by their unique combination of nominal mass and KMD. For an assigned class species, compound types with various double-bond equivalence (DBE) values were identified by the difference of integer multiples of $\mathrm{H}_{2}$. The range of DBE values of $0-40$ was allowed. Members of a homologous series differ by integer multiples of $\mathrm{CH}_{2}$. Each homologous series was identified by the assigned single members, with an additional limit of KMD tolerance of \pm 0.0010 (set by the user). Once all compounds have been sorted and all relationships based on the given "type" and "class" have been found, the program begins to assign elemental formulas. Molecular formulas were assigned to lower molecular weight members based solely on mass measurement to $\pm 1 \mathrm{ppm}$. Elemental compositions were assigned by a mass calculator program limited to molecular formulas consisting of up to 100 ${ }^{12} \mathrm{C}, 2{ }^{13} \mathrm{C}, 200{ }^{1} \mathrm{H}, 2{ }^{14} \mathrm{~N}, 20{ }^{16} \mathrm{O}$, and $2{ }^{32} \mathrm{~S}$. If two (or more) elemental compositions were found within the mass tolerance of $\pm 1 \mathrm{ppm}$, one formula could usually be confirmed/eliminated unequivocally by the presence/absence of the corresponding nuclide containing one ${ }^{13} \mathrm{C}$. Because members of a homologous series differ only by integer multiples of $\mathrm{CH}_{2}$, assignment of a single member of such a series usually suffices to identify all higher-mass members.

\section{Results and discussion}

\subsection{Molecular characterization of DOM in source water}

Fig. S1a showed the representative negative ESI FT-ICR mass spectrum of the C18 extracted Mopanshan DOM in source water. The DOM mass spectrum consists of a multitude of peaks spanning the $\mathrm{m} / \mathrm{z}$ range of $200-600$ with a maximum of the peak distribution at around $\mathrm{m} / \mathrm{z}$ 351. A strong predominance of odd over even mass ions was observed across the entire mass range, indicating that zero or an even number of nitrogen was included in the molecules. The presence of the isotopic peaks at $1.00335 \mathrm{~m} / \mathrm{z}$ units (the mass of a neutron) higher than the parent peaks at each even $\mathrm{m} / \mathrm{z}$ indicated that the peaks are singly charged, which is similar to previous findings for DOM (Kujawinski et al., 2002; Stenson et al., 2003). Typical mass spacing patterns such as $14.0156 \mathrm{Da}$ for $\mathrm{CH}_{2}-$ groups and an increase of $36.4 \mathrm{mDa}$ for the replacement of $\mathrm{O}$ by $\mathrm{CH}_{4}$ were observed for the $\mathrm{C} 18$ extract of source water. This implied that DOM in Mopanshan source water may be largely composed of molecules belonging to chemically related families, or homologous series, which have also been described by other researchers for various humic-rich DOM samples (Stenson et al., 2003; Hertkorn et al., 2008; Kim et al., 2006; Reemtsma et al., 2006). Close-up views of expanded mass spectra at the nominal masses 351 of the source water DOM are exemplarily shown in Fig. 1a. Detection of multiple peaks at each nominal mass demonstrated the molecular complexity of DOM since each peak represents at least one or 


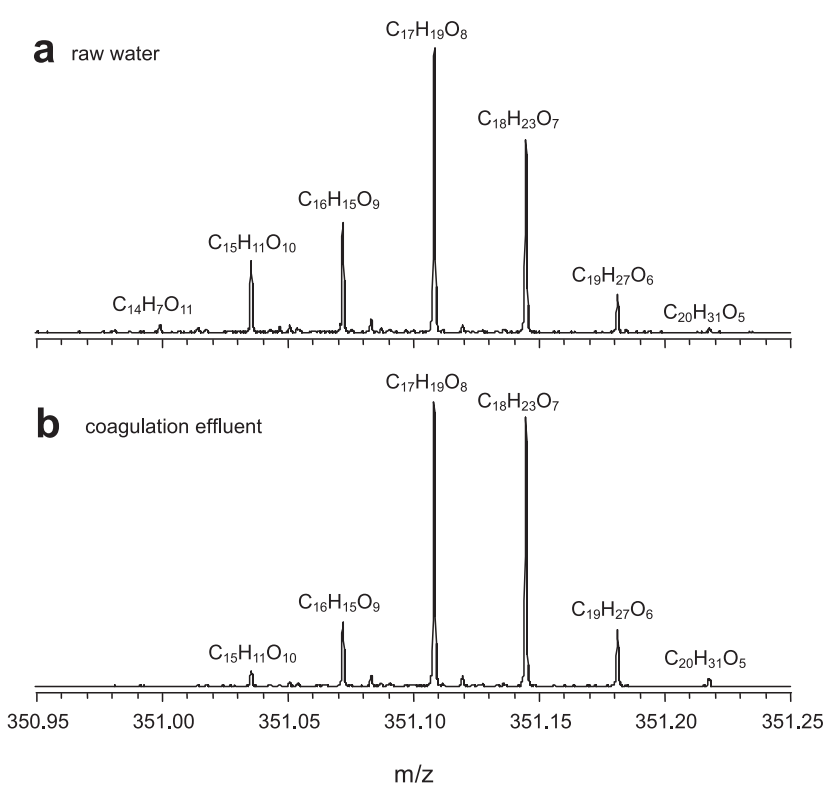

Fig. 1 - Exemplary negative-ion ESI FT-ICR MS spectra expanded at nominal mass 351 of (a) raw water and (b) coagulation effluent.

more, or even millions structures. The resolving power was $>420,000$ (full width half maximum) at nominal mass 351 . The distinct high-resolution characteristics of abundant peaks allowed the assignment of a unique elemental composition to each peak in the mass spectrum. Various $\mathrm{C}, \mathrm{H}, \mathrm{O}$-only class species, nitrogen class species and sulfur class species were identified in the source water. However, as shown in Fig. 1a, it was clear that the majority of peaks result from $\mathrm{C}, \mathrm{H}$, O-only compounds in the DOM, which is similar to other terrestrial samples (Kujawinski et al., 2002; Koch et al., 2005; Hertkorn et al., 2007; Sleighter and Hatcher, 2008). Therefore, data analysis was only applied to C, H, O-only components.

It should be noted that, in this study, C18 solid phase extraction (SPE) was used to isolate and concentrate the NOM samples, and for desalting because the ESI FT-ICR MS analysis requires a very low salt content of the samples. Only molecules which can be adsorbed on C18 and from those only molecules which can be desorbed by an organic solvent were analyzed by mass spectrometry. Highly hydrophilic (incomplete adsorption) or highly hydrophobic (incomplete desorption) molecules were not considered. In addition, the resulting mass spectrum can strongly depend on the ESI negative ionization methods used in this study. Depending on the sample, ESI positive mode or other ionization methods, such as atmospheric pressure chemical ionization (APCI) and atmospheric pressure photo ionization (APPI), can give very different mass spectra for the same sample (Hertkorn et al., 2008; Sleighter and Hatcher, 2007).

The molecular composition of DOM can be visualized in a van Krevelen diagram (van Krevelen, 1950) in which individual molecular formulas are plotted on the basis of their molar $\mathrm{H} / \mathrm{C}$ and $\mathrm{O} / \mathrm{C}$ ratios. The unique $\mathrm{H} / \mathrm{C}$ and $\mathrm{O} / \mathrm{C}$ ratios for each formula align and fall at a certain point on the diagram, reflecting the possible types of molecules such as lignin, tannin and cellulose. The stoichiometric ranges used to establish boundaries of the classification in such (van Krevelen) diagrams for the components found in natural organic matter (NOM) are quite variable in the literature (Ohno et al., 2010). Fig. 2 showed the van Krevelen diagram of the source water DOM overlain with the DOM in coagulation effluent. It appears that there is a primary contribution of peaks in the source water that corresponds to biopolymers such as lignin (O/C 0.2-0.6, H/C 1.0-1.5) and tannin (O/C 0.65-0.95, H/C $0.75-1.4)$.

\subsection{Removal of DOM by coagulation}

Fig. S1b showed the representative negative ESI FT-ICR mass spectrum of the C18 extracted DOM in the coagulation effluent. The distribution of peaks in Fig. S1b is very similar to that in Fig. S1b, indicating that major low molecular weight DOM remained in the coagulation effluent. However, by comparing the van Krevelen diagrams of source water and coagulation effluent (Fig. 2), it was observed that some molecules with a high O/C value were removed after coagulation. This phenomenon was more clearly shown by comparing the expanded mass spectra at the nominal mass 351 of the DOM before and after coagulation, which typifies the observed trends over the full mass spectral range (Fig. 1). The $\mathrm{C}, \mathrm{H}$, O-only compounds can be arranged into two series (series 1: $\mathrm{C}_{20} \mathrm{H}_{31} \mathrm{O}_{5}, \mathrm{C}_{19} \mathrm{H}_{27} \mathrm{O}_{6}, \mathrm{C}_{18} \mathrm{H}_{23} \mathrm{O}_{7}, \mathrm{C}_{17} \mathrm{H}_{19} \mathrm{O}_{8}, \mathrm{C}_{16} \mathrm{H}_{15} \mathrm{O}_{9}, \mathrm{C}_{15} \mathrm{H}_{11} \mathrm{O}_{10}$, $\mathrm{C}_{14} \mathrm{H}_{7} \mathrm{O}_{11}$; series 2: $\mathrm{C}_{21} \mathrm{H}_{19} \mathrm{O}_{5}, \mathrm{C}_{20} \mathrm{H}_{15} \mathrm{O}_{6}, \mathrm{C}_{19} \mathrm{H}_{11} \mathrm{O}_{7}, \mathrm{C}_{18} \mathrm{H}_{7} \mathrm{O}_{8}$ ), which are related by the replacement of $\mathrm{CH}_{4}$ against oxygen. After coagulation, for series 1 , signal of $\mathrm{C}_{14} \mathrm{H}_{17} \mathrm{O}_{11}(\mathrm{O} / \mathrm{C}, 0.78)$ disappeared, and the relative signal intensities of $\mathrm{C}_{15} \mathrm{H}_{11} \mathrm{O}_{10}$ $(\mathrm{O} / \mathrm{C}, 0.67)$ and $\mathrm{C}_{16} \mathrm{H}_{15} \mathrm{O}_{9}(\mathrm{O} / \mathrm{C}, 0.56)$ (relative to intensity of $\mathrm{C}_{17} \mathrm{H}_{19} \mathrm{O}_{8}$ ) decreased remarkably compared to those in source water; while the relative signal intensities of $\mathrm{C}_{18} \mathrm{H}_{23} \mathrm{O}_{7}(\mathrm{O} / \mathrm{C}$, 0.39), $\mathrm{C}_{19} \mathrm{H}_{27} \mathrm{O}_{6}(\mathrm{O} / \mathrm{C}, 0.32)$, and $\mathrm{C}_{20} \mathrm{H}_{31} \mathrm{O}_{5}(\mathrm{O} / \mathrm{C}, 0.25)$ (relative to intensity of $\mathrm{C}_{17} \mathrm{H}_{19} \mathrm{O}_{8}$ ) increased. For series 2, signal of $\mathrm{C}_{18} \mathrm{H}_{7} \mathrm{O}_{8}$ $(\mathrm{O} / \mathrm{C}, 0.44)$ (relative to intensity of $\mathrm{C}_{19} \mathrm{H}_{11} \mathrm{O}_{7}$ ) decreased, while the relative signal intensities of $\mathrm{C}_{20} \mathrm{H}_{15} \mathrm{O}_{6}(\mathrm{O} / \mathrm{C}, 0.39), \mathrm{C}_{21} \mathrm{H}_{19} \mathrm{O}_{5}$ $(\mathrm{O} / \mathrm{C}, 0.32)$ (relative to intensity of $\mathrm{C}_{19} \mathrm{H}_{11} \mathrm{O}_{7}$ ) increased (SI Fig. S2). Similar findings were found at other odd nominal

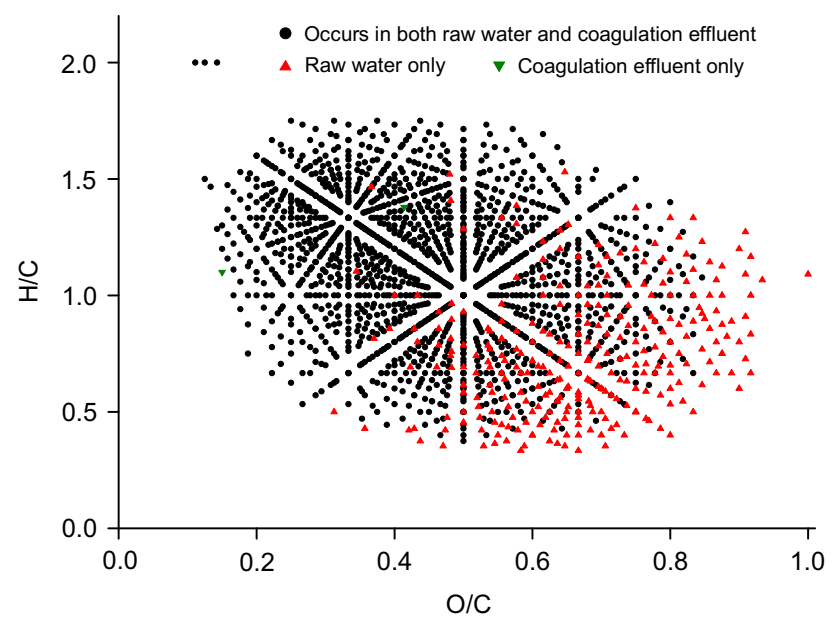

Fig. 2 - The van Krevelen diagram of the raw water DOM overlain with the coagulation effluent DOM. 
mass across the spectrum. These findings suggested that for low molecular weight DOM with the same nominal molecular weight, molecules with a high $\mathrm{O} / \mathrm{C}$ value were preferentially removed by $\mathrm{PACl}$ during coagulation.

To clearly describe the removal behaviors of the different molecules at each nominal mass, a relative reactive index (RRI) was introduced as shown in SI Fig. S3. Briefly, to calculate the RRI, firstly the relative intensity (RI) of each C, H, O-only peak $\left(P_{i}\right)$ in the same series at a given nominal mass for each sample was calculated by dividing the intensity of each peak by that of the peak $\left(P_{0}\right)$ with the highest $m / z$. RRI $I_{i}$ was defined as the ratio of $\mathrm{RI}_{i}$ of the sample after reaction to $\mathrm{RI}_{i}$ of the sample before reaction multiplied by $100 \%$. Although ESI FT-ICR MS is not a quantitative technique, the relative signal intensities of different peaks acquired under the same instrumental conditions can be compared in a semiquantitative way to differentiate similar types of components at the molecular level (Kim et al., 2003; Koch et al., 2005; Sleighter and Hatcher, 2008). The RRI compares the change of the intensity of a molecule relative to the reference molecule (peak $P_{0}$ ). Although the RRI does not indicate absolute concentrations change of a molecule, it reflects the relative concentrations change of the molecule to that of the reference molecule. So RRI could be used to evaluate the relative reactivities of different molecules within a group of isobaric molecules. In many cases, at a given nominal mass two $\mathrm{C}, \mathrm{H}$, O-only series can be observed, as exemplarily shown in Fig. 1 and Fig. S2 for the nominal mass 351. The series which contains the $\mathrm{C}, \mathrm{H}$, O-only molecule with the highest $\mathrm{m} / \mathrm{z}$ was selected as series 1 (S1). Molecules in S1 typically have higher relative intensities than those in the other $\mathrm{C}, \mathrm{H}$, O-only series (series 2, S2). Fig. 3 showed $\mathrm{CH}_{2}$ based Kendrick mass defect (KMD) analysis with RRI of raw water and coagulation effluent from odd nominal mass 201 to 599 with dataset of S1. For C, H, O-only components with the same nominal molecular weight, KMD increased as the oxygen content increases (replacements of $\mathrm{CH}_{4}$ groups by O). Thus high $\mathrm{KMD}$ values for a given nominal mass indicate extensive oxygenation (Hughey et al., 2001). Molecular information derived from the Kendrick

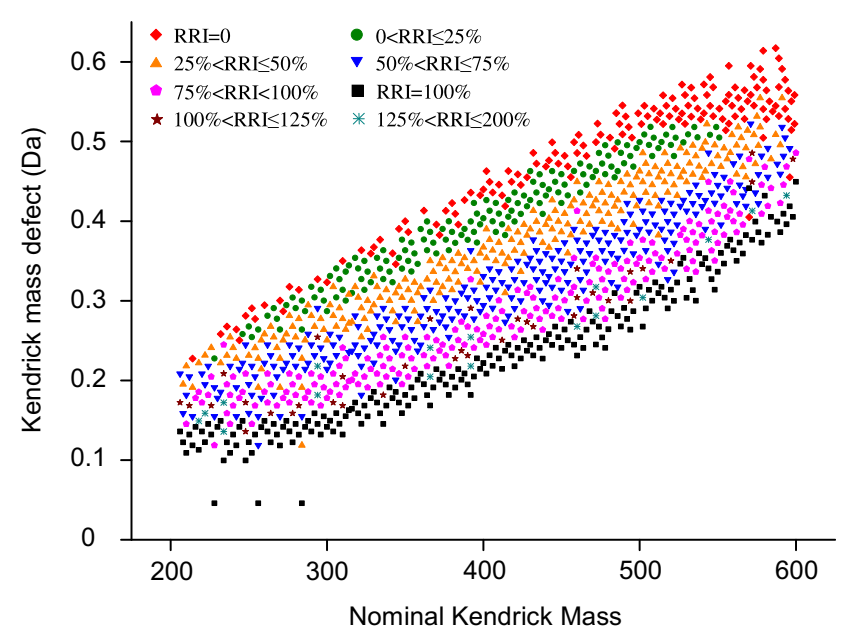

Fig. $3-\mathrm{CH}_{2}$-based Kendrick mass analysis with relative reactive index (RRI) of raw water and coagulation effluent from odd nominal mass 201 to 599 (with dataset S1). mass defect can be compactly represented with a Kendrick plot in which KMD is plotted against nominal Kendrick mass (Hughey et al., 2001). In such a plot, elemental compositions differing in DBE or number of oxygens are separated vertically, due to their different KMD values. These plots can be used quite effectively to compare the molecular characteristics of DOM samples. In this study we combined the KMD analysis and RRI to systematically evaluate the removal behaviors of the different molecules of the full mass range. It is clear that during coagulation, the components with high KMD (and thus high O/C value) has a low RRI value, suggesting that molecules with high $\mathrm{O} / \mathrm{C}$ were preferentially removed by coagulation using $\mathrm{PACl}$, leaving the molecules with low $\mathrm{O} / \mathrm{C}$ values behind. KMD analysis with RRI for dataset S2 was shown in SI Fig. S4.

Previous studies has shown that DOM with low molecular weight $(<500-700)$, which may not only serve as important precursors for DBPs (Richardson, 1998), but also promote biofilm formation in drinking water distribution, is difficult to remove by coagulation (Davis and Gloor, 1981; Chow et al., 1999; Drikas et al., 2003). Through ESI FT-ICR MS analysis, however, we found that the low molecular weight DOM with a high $\mathrm{O} / \mathrm{C}$ could be removed by $\mathrm{PACl}$ during coagulation based on their molecular structures. It is suggested that PACl directly precipitates fulvic acid over a broad $\mathrm{pH}$ range mainly through the charge neutralization-precipitation mechanism (Dempsey et al., 1984; van Benschoten and Edzwald, 1990; Yan et al., 2008). Witt et al. (2009) has shown that oxygen in Suwannee River fulvic acid is predominantly bound in carboxyl groups. So within a group of isobaric DOM molecules, those with a high O/C may contain more acidic functional groups and could be preferentially removed by PACl through the charge neutralization-precipitation mechanism. During ozonation, natural organic matter of higher molecular weight may be split into oxidized low molecular weight subunits, which are highly oxidized and contain a larger number of carboxylic groups (These and Reemtsma, 2005). So, the removal efficiency of the low molecular weight DOM by coagulation may be improved by ozone preoxidation.

\subsection{Change of DOM during chlorination}

Fig. S5 showed the van Krevelen diagram of the C18 extracted DOM in the sand filtration effluent overlain with that of the C18 extracted DOM in the coagulation effluent. Only a few points disappeared after sand filtration. Fig. S6 and S7 showed the KMD analysis with RRI for sand filtration from odd nominal mass 201 to 599 with dataset S1 and S2, respectively. For most components, RRI were within $75-100 \%$, indicating there was no significant difference between sand filtration effluent and coagulation effluent. Fig. S1d shows the representative negative ESI FT-ICR mass spectrum of the C18 extracted of chlorination effluent. The distribution of peaks in Fig. S1d is very similar to that in Fig. S1c. A slight change in relative intensities of peaks between chlorination effluent and sand filtration effluent was observed in a close-up view of expanded mass spectra at the nominal mass 251 (SI, Fig. S8). After chlorination, the relative signal intensities of compounds with a high $\mathrm{O} / \mathrm{C}$ value $\left(\mathrm{C}_{11} \mathrm{H}_{7} \mathrm{O}_{7}, \mathrm{O} / \mathrm{C}, 0.6\right)$ slightly increased, while compounds with a low $\mathrm{O} / \mathrm{C}$ value $\left(\mathrm{C}_{15} \mathrm{H}_{25} \mathrm{O}_{3}\right.$, $\mathrm{O} / \mathrm{C}, 0.2)$ decreased. This observation was confirmed by the 
KMD analysis with RRI of sand filtration effluent and chlorination effluent from odd nominal mass 201 to 599 (SI, Fig. S9 and S10). The KMD analysis showed that, in most cases, DOM molecules with a high KMD (high O/C) increased relative to those with a low KMD (low O/C) during chlorination, suggesting that within a group of isobaric molecules, the low O/C ones appeared to be more reactive toward chlorine. This observation corresponds to expectation when thermodynamics are considered, because oxidation of the least oxidized molecule provides the largest gain in energy. An explanation can be deduced from the potential structures of these molecules. The more oxidized molecules may contain more carboxylate groups (Witt et al., 2009) and have less carbon atoms available to form the carbon skeleton. As shown in SI Fig. S11, most of the carbon skeleton in $\mathrm{C}_{11} \mathrm{H}_{8} \mathrm{O}_{7}$ is sterically shielded by the carboxylate groups. Contrary to that, the least oxidized molecule of this series $\left(\mathrm{C}_{15} \mathrm{H}_{24} \mathrm{O}_{3}\right)$ may have a quite extended carbon skeleton, resulting in a more accessible molecular structure for free chlorine. This was in agreement with These's study on reactivity of fulvic acid molecules
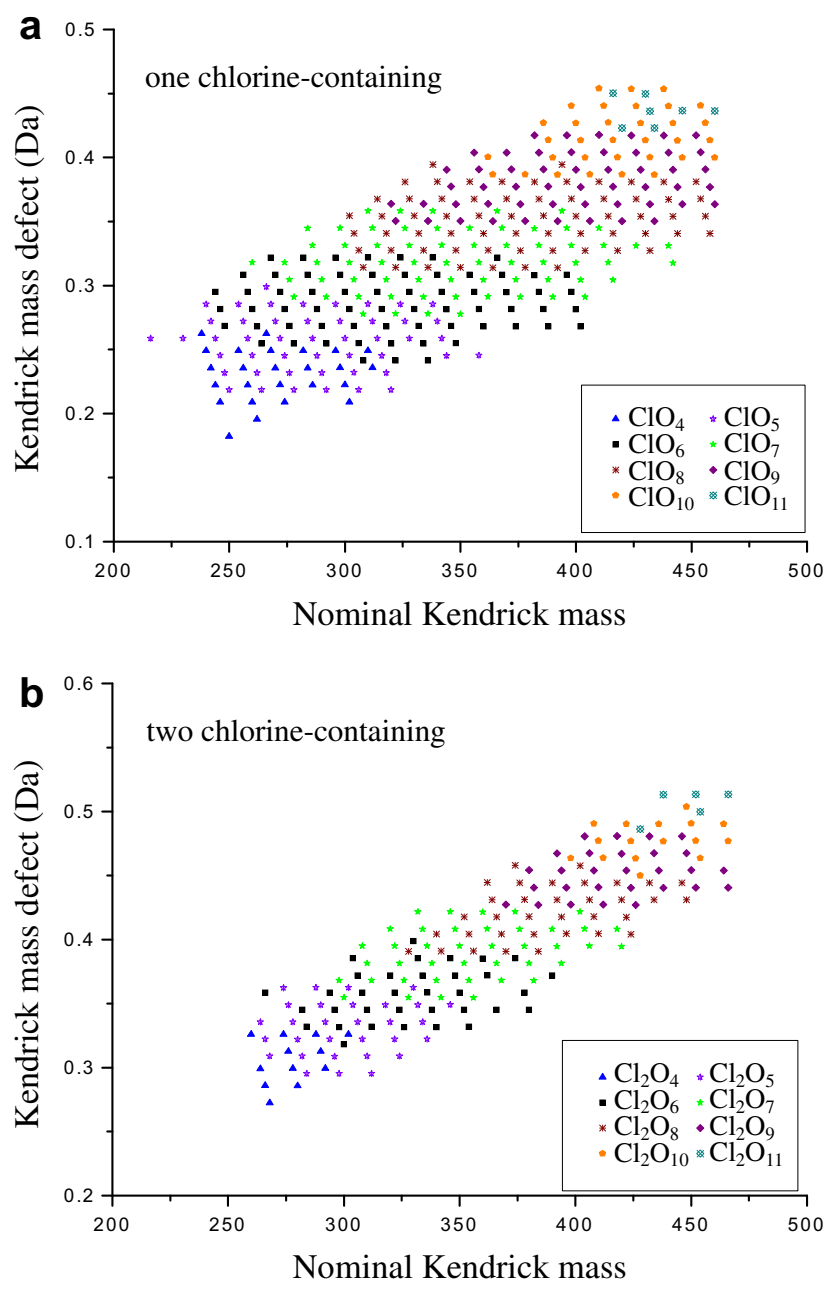

Fig. $4-\mathrm{CH}_{2}$-based Kendrick mass analysis of chlorinecontaining DBPs. (a) one-chlorine containing products, $\mathrm{ClO}$ species were plotted in series $\mathrm{ClO}_{4}-\mathrm{ClO}_{11}$ and (b) two chlorine-containing products, $\mathrm{Cl}_{2} \mathrm{O}$ species were plotted in series $\mathrm{Cl}_{2} \mathrm{O}_{4}-\mathrm{Cl}_{2} \mathrm{O}_{11}$. during ozonation (These and Reemtsma, 2005) and our previous study on transformation of NOM during chlorination (Zhang et al., 2012).

Due to its ultrahigh resolution capacity, the FT-ICR MS spectra also allow determination of chlorination products that occurred at exact masses not detected before chlorination (Zhang et al., 2012). Clear signals of newly formed products were obtained in the mass spectra at odd nominal masses, as exemplarily shown in Fig. S12. Some of the newly formed molecules also have a characteristic mass difference of

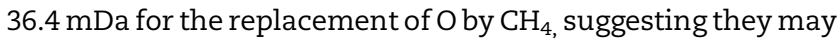
be yielded from homologous series of parent DOM compounds. However, molecular formulas of these newly formed compounds cannot be identified by accurate mass calculation using only $\mathrm{C}, \mathrm{H}, \mathrm{O}, \mathrm{N}$ and $\mathrm{S}$, suggesting that the newly formed products may contain other atoms, such as chlorine. So accurate mass analysis using $\mathrm{C}, \mathrm{H}, \mathrm{O}, \mathrm{N}, \mathrm{S}, \mathrm{P}$ and $\mathrm{Cl}$ was performed and formulas for four peaks $\left(\mathrm{C}_{11} \mathrm{H}_{9} \mathrm{Cl}_{2} \mathrm{O}_{6}^{-}, \mathrm{C}_{12} \mathrm{H}_{13} \mathrm{Cl}_{2} \mathrm{O}_{5}^{-}\right.$, $\mathrm{C}_{11} \mathrm{H}_{12} \mathrm{ClO}_{8}^{-}$and $\mathrm{C}_{12} \mathrm{H}_{16} \mathrm{ClO}_{7}^{-}$) in Fig. $\mathrm{S} 12$ were assigned by accurate mass analysis and isotopic pattern matching.

In this work, totally 357 peaks containing one chlorine and 199 peaks containing two chlorine were assigned at a high level of confidence by accurate mass analysis and Kendrick analysis. Fig. 4 shows the $\mathrm{CH}_{2}$-based Kendrick mass analysis of the newly formed chlorine-containing products after chlorination. The newly formed chlorine-containing products can be arranged into $\mathrm{ClO}_{4}-\mathrm{ClO}_{11}$ (Fig. $4 \mathrm{a}$ ) and $\mathrm{Cl}_{2} \mathrm{O}_{4}-\mathrm{Cl}_{2} \mathrm{O}_{11}$ (Fig. 4b) class species. Detailed molecular formula data for these chlorinated components are listed in SI Table S2 (also available as a spreadsheet file in SI for download). Fig. 5 showed the van Krevelen diagram of chlorine-containing molecules overlain with $\mathrm{C}, \mathrm{H}$, O-only molecules. All chlorine-containing molecules were overlaid with corresponding $\mathrm{C}, \mathrm{H}$, O-only molecules, suggesting the chlorine containing molecules might be formed from the corresponding $\mathrm{C}, \mathrm{H}$, O-only molecules (supposing that the formation of chlorine-containing

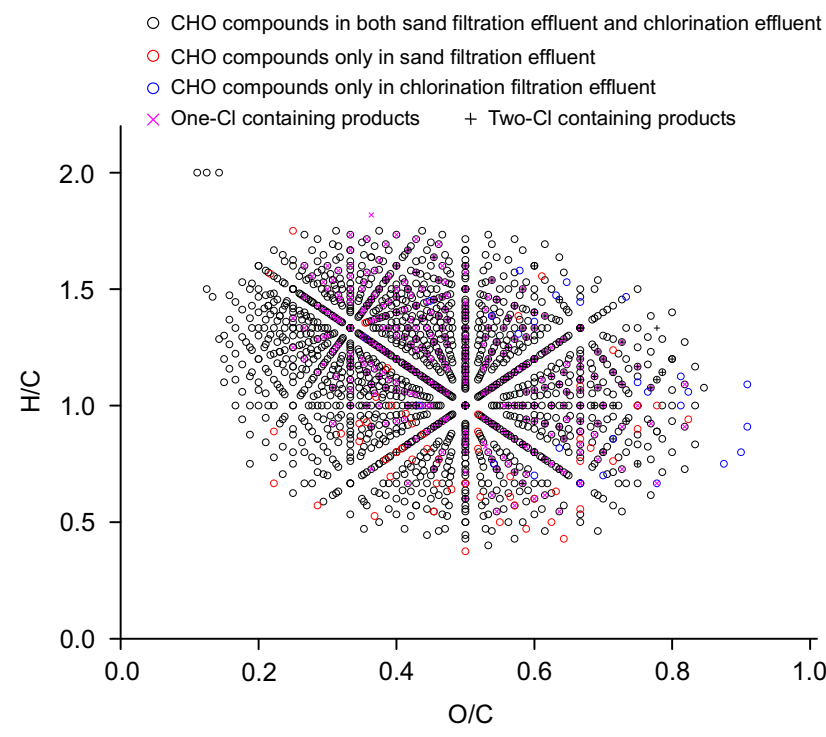

Fig. 5 - The van Krevelen diagram of the sand filtration effluent DOM overlain with the chlorination effluent DOM and chlorine containing products. 
molecules does not involve breaking down large $\mathrm{C}, \mathrm{H}$, O-molecules) during chlorination.

Although chlorinated products as a result of the reaction of the disinfectant chlorine with DOM in raw water have been intensively studied over the past 30 years, only about $50 \%$ of the TOX formed during chlorination has been chemically identified to individual species (Richardson, 2003; Zhang et al., 2005; Hua and Reckhow, 2007). Richardson compiled a review on drinking water DBPs in which she listed approximately 600 chlorinated DBPs, and almost all of them were identified by gas chromatography/mass spectrometry (GC/MS) or derivatization-GC/MS (Richardson, 1998; Richardson et al., 2007). However, even with derivatization, GC/MS generally is not amenable to the detection of highly polar compounds. The chlorinated products detected in this study fall in a molecular mass range from 200 to $500 \mathrm{Da}$, and may be rich in carboxylic and phenolic groups, clearly differing from the commonly known small molecular DBPs in drinking water. Although it is still difficult to obtain structural information of these new chlorine-containing products, our results demonstrated that ESI FT-ICR MS is a powerful tool for the detection of the electrospray ionizable chlorine-containing DBPs in finished water.

\section{Conclusions}

This investigation employed ESI FT-ICR MS to study the behavior of low molecular weight DOM during conventional drinking treatment process. The following conclusions can be drawn from this study:

1. The ultrahigh resolution and mass accuracy of ESI FT-ICR MS provides a tool with the power to examine individual molecule within DOM, and enables the study of the behavior of individual molecules of DOM during drinking water treatment processes.

2. Various $\mathrm{C}, \mathrm{H}, \mathrm{O}$-only class species were the major components in the source water. The van Krevelen diagram showed that compounds corresponding to biopolymers such as lignin and tannin were the most abundant components in the sample.

3. For the first time, it was found that within an isobaric group, the DOM molecules with a high degree of oxidation (high O/C value) were preferentially removed during coagulation by $\mathrm{PACl}$, while those with a lower degree of oxidation (low O/C value) were found to be more reactive toward chlorine.

4. A total of 357 peaks containing one chlorine and 199 peaks containing two chlorine were detected in actual waterworks at a high level of confidence by accurate mass analysis and Kendrick analysis, suggesting that attention to these unknown chlorinated DBPs may be required in further studies.

\section{Acknowledgments}

We thank the anonymous reviewers for their constructive comments and kind help in improving the quality of this manuscript. This work was supported by the National Natural
Science Foundation of China (grant no. 50938007 and 51008294) and Funds for Major Science and Technology Program for Water Pollution Control and Treatment (2009ZX07419-001).

\section{Appendix A. Supplementary material}

Supplementary material related to this article can be found online at http://dx.doi.org/10.1016/j.watres.2012.07.004.

\section{R E F E R E N C E S}

Abbt-Braun, G., Lankes, U., Frimmel, F., 2004. Structural characterization of aquatic humic substances - The need for a multiple method approach. Aquatic Sciences 66 (2), 151-170.

Aoustin, E., Schäfer, A.I., Fane, A.G., Waite, T.D., 2001. Ultrafiltration of natural organic matter. Separation and Purification Technoloy 22-23, 63-78.

Berwick, L., Greenwood, P.F., Smernik, R.J., 2010. The use of MSSV pyrolysis to assist the molecular characterisation of aquatic natural organic matter. Water Research 44 (10), 3039-3054.

Chow, C.W.K., van Leeuwen, J.A., Drikas, M., Fabris, R., Spark, K.M., Page, D.W., 1999. The impact of the character of natural organic matter in conventional treatment with alum. Water Science and Technology 40, 97-104.

Cook, R.L., 2004. Coupling NMR to NOM. Analytical and Bioanalytical Chemistry 378 (6), 1484-1503.

Davis, J.A., Gloor, R., 1981. Adsorption of dissolved organics in lake water by aluminum oxide. Effect of molecular weight. Environmental Science and Technology 15 (10), 1223-1229.

Dempsey, B.A., Ganho, R.M., O'Melia, C., 1984. The coagulation of humic substances by means of aluminum salts. Journal of the American Water Works Association 76 (4), 141-150.

Drikas, M., Chow, C.W.K., Cook, D., 2003. The impact of recalcitrant organic character on disinfection stability, trihalomethane formation and bacterial regrowth: an evaluation of magnetic ion exchnage (MIEX) and alum coagulation. Journal of Water Supply: Research \& TechnologyAQUA 52, 475-487.

Gonsior, M., Peake, B.M., Cooper, W.T., Podgorski, D., D'Andrilli, J., Cooper, W.J., 2009. Photochemically induced changes in dissolved organic matter identified by ultrahigh resolution Fourier transform ion cyclotron resonance mass spectrometry. Environmental Science and Technology 43 (3), 698-703.

Hem, L., Efraimsen, H., 2001. Assimilable carbon in molecular weight fractions of natural organic matter. Water Research 35, 1106-1110.

Hertkorn, N., Ruecker, C., Meringer, M., Gugisch, R., Frommberger, M., Perdue, E.M., Witt, M., Schmitt-Kopplin, P., 2007. High-precision frequency measurements: indispensable tools at the core of the molecular-level analysis of complex systems. Analytical and Bioanalytical Chemistry 389 (5), 1311-1327.

Hertkorn, N., Frommberger, M., Witt, M., Koch, B.P., SchmittKopplin, P., Perdue, E.M., 2008. Natural organic matter and the event horizon of mass spectrometry. Analytical Chemistry 80 (23), 8908-8919.

Hua, G., Reckhow, D.A., 2007. Characterization of disinfection byproduct precursors based on hydrophobicity and molecular size. Environmental Science and Technology 41 (9), 3309-3315.

Hughey, C.A., Hendrickson, C.L., Rodgers, R.P., Marshall, A.G., Qian, K., 2001. Kendrick mass defect spectrum: a compact 
visual analysis for ultrahigh-resolution broadband mass spectra. Analytical Chemistry 73, 4676-4681.

Kim, S., Kramer, R.W., Hatcher, P.G., 2003. Graphical method for analysis of ultrahigh-resolution broadband mass spectra of natural organic matter, the van Krevelen diagram. Analytical Chemistry 75, 5336-5344.

Kim, S., Kaplan, L.A., Hatcher, P.G., 2006. Biodegradable dissolved organic matter in a temperate and a tropical stream determined from ultra-high resolution mass spectrometry. Limnology and Oceanography 51 (2), 1054-1063.

Knuutinen, J., Virkki, L., Mannila, P., Mikkelson, P., Paasivirta, J., Herve, S., 1988. High-performance liquid chromatographic study of dissolved organic matter in natural waters. Water Research 22 (8), 985-990.

Koch, B.P., Witt, M., Engbrodt, R., Dittmar, T., Kattner, G., 2005. Molecular formulae of marine and terrigenous dissolved organic matter detected by electrospray ionization Fourier transform ion cyclotron resonance mass spectrometry. Geochimica et Cosmochimica Acta 69 (13), 3299-3308.

Kujawinski, E.B., Hatcher, P.G., Freitas, M.A., 2002. Highresolution Fourier transform ion cyclotron resonance mass spectrometry of humic and fulvic acids: improvements and comparisons. Analytical Chemistry 74, 413-419.

Kujawinski, E.B., Del Vecchio, R., Blough, N.V., Klein, G.C., Marshall, A.G., 2004. Probing molecular-level transformations of dissolved organic matter: insights on photochemical degradation and protozoan modification of DOM from electrospray ionization Fourier transform ion cyclotron resonance mass spectrometry. Marine Chemistry 92 (1-4), 23-37.

Li, C., Benjamin, M.M., Korshin, G.V., 2000. Use of UV spectroscopy to characterize the reaction between NOM and free chlorine. Environmental Science and Technology 34 (12), 2570-2575.

McDonald, S., Bishop, A.G., Prenzler, P.D., Robards, K., 2004. Analytical chemistry of freshwater humic substances. Analutica Chimica Acta 527, 105-124.

Minor, E., Stephens, B., 2008. Dissolved organic matter characteristics within the lake superior watershed. Organic Geochemistry 39 (11), 1489-1501.

Newcombe, G., Drikas, M., Assemi, S., Beckett, R., 1997. Influence of characterised natural organic material on activated carbon adsorption: I. Characterisation of concentrated reservoir water. Water Research 31 (5), 965-972.

Ohno, T., He, Z., Sleighter, R., Honeycutt, C.W., Hatcher, P.G., 2010. Ultra high resolution mass spectrometry and indicator species analysis to identify marker components of soil- and plant biomass-derived organic matter fractions. Environmental Science and Technology 44 (22), 8594-8600.

Qian, K., Rodgers, R.P., Hendrickson, C.L., Emmett, M.R., Marshall, A.G., 2001. Reading chemical fine print: resolution and identification of 3000 nitrogen-containing aromatic compounds from a single electrospray ionization Fourier transform ion cyclotron resonance mass spectrum of heavy petroleum crude oil. Energy Fuels 15, 492-498.

Reemtsma, T., These, A., Springer, A., Linscheid, M., 2006. Fulvic acids as transition state of organic matter: Indications from high resolution mass spectrometry. Environmental Science and Technology 40 (19), 5839-5845.

Richardson, S.D., 1998. Drinking water disinfection by-products. In: Meyers, R.A. (Ed.), The Encyclopedia of Environmental Analysis and Remediation. John Wiley \& Sons, New York.

Richardson, S.D., 2003. Disinfection by-products and other emerging contaminants in drinking water. Trends in Analytical Chemistry 22, 666-684.
Richardson, S.D., Plewa, M.J., Wagner, E.D., Schoeny, R., DeMarini, D.M., 2007. Occurrence, genotoxicity, and carcinogenicity of regulated and emerging disinfection by-products in drinking water: a review and roadmap for research. Mutation Research-Reviews in Mutation Research 636 (1-3), 178-242.

Roccaro, P., Vagliasindi, F.G.A., Korshin, G.V., 2009. Changes in NOM fluorescence caused by chlorination and their associations with disinfection by-products formation. Environmental Science and Technology 43 (3), 724-729.

Shi, Q., Dong, Z., Zhang, Y., Zhao, S., Xu, C., 2008. Data processing of high-resolution mass spectra for crude oil and its distillations. Journal of Instrumental Analysis 27 (Suppl. 1), 246-248

Sleighter, R.L., Hatcher, P.G., 2007. The application of electrospray ionization coupled to ultrahigh resolution mass spectrometry for the molecular characterization of natural organic matter. Journal of Mass Spectrometry 42 (5), 559-574.

Sleighter, R.L., Hatcher, P.G., 2008. Molecular characterization of dissolved organic matter (DOM) along a river to ocean transect of the lower Chesapeake Bay by ultrahigh resolution electrospray ionization Fourier transform ion cyclotron resonance mass spectrometry. Marine Chemistry 110 (3-4), 140-152.

Sleighter, R.L., McKee, G.A., Hatcher, P.G., 2009. Direct Fourier transform mass spectral analysis of natural waters with low dissolved organic matter. Organic Geochemistry 40 (1), 119-125.

Stenson, A.C., Marshall, A.G., Cooper, W.T., 2003. Exact masses and chemical formulas of individual Suwannee River fulvic acids from ultrahigh resolution electrospray ionization Fourier transform ion cyclotron resonance mass spectra. Analytical Chemistry 75 (6), 1275-1284.

These, A., Reemtsma, T., 2005. Structure-dependent reactivity of low molecular weight fulvic acid molecules during ozonation. Environmental Science and Technology 39 (21), 8382-8387.

Thurman, E.M., Malcolm, R.L., 1981. Preparative isolation of aquatic humic substances. Environmental Science and Technology 15 (4), 463-466.

van Benschoten, J.E., Edzwald, J.K., 1990. Chemical aspects of coagulation using aluminum salts-II. Coagulation of fulvic acid using alum and polyaluminum chloride. Water Research 24 (12), 1527-1535.

van Krevelen, D.W., 1950. Graphical statistical method for the study of structure and reaction processes of coal. Fuel 19, 269-284.

Witt, M., Fuchser, J., Koch, B.P., 2009. Fragmentation studies of fulvic acids using collision induced dissociation Fourier transform ion cyclotron resonance mass spectrometry. Analytical Chemistry 81 (7), 2688-2694.

Yan, M., Wang, D., Ni, J., Qu, J., Chow, C.W.K., Liu, H., 2008. Mechanism of natural organic matter removal by polyaluminum chloride: effect of coagulant particle size and hydrolysis kinetics. Water Research 42, 3361-3370.

Zhang, H., Zhang, Y., Shi, Q., Hu, J., Chu, M., Yu, J., Yang, M., 2012. Study on transformation of natural organic matter in source water during chlorination and its chlorinated products using ultrahigh resolution mass spectrometry. Environmental Science and Technology 46 (8), 4396-4402.

Zhang, X., Minear, R.A., Barrett, S.E., 2005. Characterization of high molecular weight disinfection byproducts from chlorination of humic substances with/without coagulation pretreatment using UF-SEC-ESI-MS/MS. Environmental Science and Technology 39 (4), 963-972. 